\title{
Analysis on the Orientation of File Management
}

\author{
Yun $\mathrm{Hu}$ \\ Qilu Normal University (China Shandong250200)
}

Keywords: File management; Orientation; Colleges and Universities

\begin{abstract}
With the continuous improvement of the modernization level of our country in recent years, the quantity and quality of higher education in schools have steadily improved, in which for the university archives management work also put forward higher requirements. Combined with the author's practical experience, the author introduces the positioning, the current university archives personnel management thinking and the future direction for improvement, in order to improve the archives management team construction level and promote the university archives management work carried out in an orderly manner.

As an important part of the organization and personnel work in colleges and universities, archives management not only includes the file management of university staff, but also includes the management of student files and the management of other service personnel on campus. Because it is directly related to the management of archives and affects the efficiency of the implementation of the overall management of colleges and universities, it also has a certain relationship with the safety of staff at school, so colleges and universities must pay attention to it. From the orientation of the archives management in colleges and universities, it can often reflect the importance of the school top management in the management of file, and also shows the efficiency and quality of the development and completion of file work.
\end{abstract}

\section{Part One Theoretical Analysis on the Orientation of File Management in Colleges and Universities in China}

According to the current experience and present situation of archives management work in Chinese universities, the most common positioning theory of archives management in colleges and universities can be divided into the following three modes:

\section{Archival Management Work Center Theory}

The center theory of file management means that when the core portion is not in the work of colleges and universities and the business should also serve the core of the university management, the file management theory tends to pay more attention to the archives management, despise other management work, and encourage and guide the work of file management from the edge to the center of the management mode, so to be able to achieve more by the management function of archives archives management, laying the foundation and premise for the efficient development of promoting the management work.

\section{Marginal Theory of File Management}

The theory of the file management work mainly means that edge is just a small part of the college management that have very little influence and its auxiliary role needs not to be as a core to carry out the work of management and implementation. Similar to the edge of the archives management work, many scholars in some articles also mentioned that they think the unified file management work should be marginalized even in a situation which is not essential in the management of colleges and universities, this is the cognition and orientation of archives management theory on the edge of the file management work.

\section{Basic Theory of File Management}

The basic theory of archives management work through the main task means that university file management work is to do a good job of supporting the work foundation of the university personnel training and social functions of universities, research and development work, so that the foundation of university file management belongs to the whole work of universities. Influence of putting forward the theory foundation for the management of the main file attachment is related content in 
China in 1989 by the State Education Commission issued under the gradually developed and derived, which has guiding effect and is very important for the basic orientation of archives management.

As the author itself, combined with the actual work experience, because different universities have different stages of development and the actual situation, the above three theories has its characteristics and significance of the launch, but the pattern has defects and shortcomings, so it should not be denied or direct support.

So I think that only choose more for their own college file management of the construction of the theory is more appropriate theory, not excessive pursuit of a theory of the effect in the process of construction, advantages and should be integrated into three of archives work, such as excessive weakening of archives management in colleges and universities, the edge of the archives management theory work reduce the actual utility of archives management for the development of large scale that is clearly inappropriate, with the expansion of the university scale, the management work has been carried out, while if the work of archives management in the center theory of file management work in high school lead to a waste of resources, the actual effect of university development will happen, and how to choose the location the archives management work in colleges and universities also start from their own tailor-made for good.

\section{Part Two Task Focus of Archives Management}

\section{Establishing the Core Tasks of Colleges And Universities}

If colleges and universities want to carry out the relevant work of file management, it must first determine the core tasks of colleges and universities. As the cradle of the training and education of social talents, the institutions of higher learning in China has a very important influence on the realization of socialist modernization. In order to realize the talent level of professional quality and enhance the overall quality level, the most effective means to carry out teaching activities, according to China's current social demand for talent with the employer, personnel can be divided into talent for teaching, research and teaching research, as other work in colleges and universities, its development must be recognized and the initiative is the core task of service to improve the way of achieving the level of University education.

\section{Serving Teaching}

In any related work, it must focus on the teaching work, this is due to the core task of the university itself that is the basis and guarantee of teaching, and improving the quality of teaching is to achieve the development of universities. On the other hand, the teaching work in colleges and universities is the guarantee for the realization of other jobs, and also the cornerstone of survival and development. File management work is very complex, and multi part includes the student records management, management of scientific research archives, archives management and staff of the school history file management and so on, through the archives management not only can effectively enhance the efficiency of school management, reduce the tendency of information chaos influence subsequent decision, but also can effectively promote the dissemination and inheritance based on the realization of campus culture. According to the different management it can be seen that the different stages of the university for the archives management are not the same attitude, this is because in the founding process, there are different stages in the objectives and requirements of teaching quality in different stages of ascension are not the same, so in order to continue to serve the teaching work the emphasis of archives work, they should make the appropriate changes.

\section{Doing Good Job of Positioning Oneself}

For the problem of localization of archives management of many scholars in China have put forward their own views, which is nothing more than the basic orientation and non basic positioning of the argument, in my opinion, university archives management itself should not be based or non based qualitative, and more emphasis should be placed on the work itself including the impact on scientific research teaching records and personnel management, so as to digging out the work is not based or basic qualitative conversion that can be achieved between the two. 


\section{Part Three Development Trend of File Management}

Through the analysis of the development orientation of file work in colleges and universities, it can be seen that whether the choice of university file management positioning, its service in the management of teaching in colleges and Universities is based on the core principles which will not be affected, according to the core principles of archives management work, the future trend of development is divided into the following modes:

\section{Changing the Function of Archives Management Center}

Most of the current colleges and universities are gradually realize the importance of transformation on the functions of archives management center, especially now with the advent of information age, modern information technology has achieved unprecedented development, and the office automation is the trend and expanding the scale. As the archives management of colleges and universities, the characteristics of short and fast document circulation cycle are gradually emerging. Based on these documents and information sharing, it can not only improve the efficiency and speed of document processing, file management will enhance the stability but also can greatly promote the modernization of management and network by realizing the transformation of the service concept to achieve the functions of file management center and business development providing the possibility of more.

\section{Establishing Campus Information Sharing Platform}

File management center itself has a large number of basic information database, sharing platform can not only promote access to information through the establishment of campus information, but also makes the information can revitalize the value of information not to be wasted and to fully mobilize the substantial role of file management access to information platform that can not only help the department of archive management in multi-angle and full range of expansion through the construction of campus information sharing, but also for the realization of archives and management center which has become a central and shared and ultimately changing the traditional management mode of campus information network, with electronic information instead of paper media effect, it can make a positive contribution to promote the overall level of service quality management in campus.

\section{To be Cultural Heritage of the Post}

Campus culture and atmosphere in colleges and universities play an important role in improving their teaching quality, improving their brand value and promoting their own development. As a crystallization of the construction and efforts of teachers and students, the recording and inheritance of campus culture is the record and inheritance of the history of campus development. The archives management departments of colleges and universities often play an important role in the inheritance of university culture, which mainly displays in the following aspects:

Firstly, it provides a strong reference for the humanistic construction in colleges and universities. The reference development history of colleges and universities in China is not difficult to find, but with higher colleges and universities teaching quality often has a campus history and culture that is very long, there are writers, scientists and industry personnel support, but to the contrary, while the archives management work is not the content of these records and expansion. If lose the record of the support of campus culture and the construction of humanities, the campus will lose the soil of history and culture development, so the role of university file management play an important role in the inheritance of university culture.

Secondly, to be the link between University and society. In many cases, we compare universities to ivory towers. In the ivory tower, students can thrive. But with the progress of society and development we are beginning to realize that the students can not be fully protected in the campus, with the continuous development of society and the college of information technology increasingly close ties, as inheritance and record of the campus culture of the inn, and file management department also assumed the role of a bridge between the campus and the society the link by direction of the comprehensive influence of campus culture, knowledge and ideas to the society to expand the transmission but also the future of archives management work. 


\section{Conclusion}

In summary, the management of university archives is the foundation of realizing high efficiency management and safety management, but also the foundation and guarantee for the construction of efficient implementation of overall quality, and its position has influence and restrict the development of colleges and universities. From the essence of archives management, its location should not be confined to the management of colleges and universities should through the internal mode and function of change of location optimization and good judgment, which requires the file management personnel engaged in related work to have the pioneering spirit, taking the initiative to play innovation consciousness with the spirit of innovation, transformation of archives management ideas and enhancing the function of archives management in the management of students, but also laying the foundation and guarantee for the construction of a comprehensive development of colleges and universities.

\section{Reference}

[1] Jingjing Chen.Orientation and development of personnel file management personnel in Colleges and Universities[J].Portland World,2012,35:77-78.

[2] Yabo Zhang.Target orientation and effective way of government archives management[J].Commercial Culture(Academic Edition),2008,12:193-194.

[3] Xiaoying Liu.Research on understanding and thinking of archives management in the work of colleges and Universities[J].Technological Wind,2015,01:255.

[4] Jiejun Hu.Research on understanding and thinking of archives management in the work of colleges and Universities[J].Chinese Management Informatization,2015,11:208-209.

[5] Qianqian Niu.Research on the role of archivists[D].Shandong University,2015.

[6] Jun Lin.Target orientation and thinking of archives management[J]. China Educational Technology Equipment,2014,18:72-73. 